\title{
GOMA: STORIES OF STRENGTH AND SORROW FROM EASTERN CONGO
}

\author{
Theodore Trefon and Noël Kabuyaya- \\ Zed Books \\ London, 2018
}

Goma - Stories of strength and sorrow sheds light on how Goméens, the inhabitants of Goma, perceive and breathe life into the city that offers them many opportunities, but that is also a potential source of insecurity. It tells the history of Goma, roughly between the I980s and today, using the individual stories of twelve of its inhabitants. This life-history approach works well in most places and materializes Goma through the eyes of its inhabitants in all its contradictions. The twelve live-histories present a rich and diversified tapestry of experiences, as the protagonists are well chosen and representative of Goma's urban composition. Centring people's experiences, and their resilience in dealing with difficulties - actively (re)shaping the urban environment, is refreshing. That their stories form the core of the book makes it an engaging and accessible read, one unhindered by jargon or an overload of theory.

The selected live-stories capture the contradictions of living in Goma, 'strength and sorrow' in the subtitle of the book, or 'danger and opportunity', as emphasized well in the introduction. Yet, the framing of these contradictions by the authors is sometimes less elegant. The openingparagraph of the introduction for example reads: "Suffering, ethnic hatred, poverty and violence are idioms commonly used to describe the social context of Goma and its North Kivu hinterland both by local people and by the swarms of international do-gooders struggling to bring about peace and security. Jealousy, mistrust and fear are other sentiments commonly expressed." While they propose to contrast such "dominant discourses of violence" by stories of resilience and agency, at times they still come close to reiterating the eastern DRC as a kind of "heart of darkness". Some sweeping statements further reduce complex realities to catchy one-liners. The prose which sometimes has a journalistic feel, reinforces this. What to think about this statement for example: "The physically unthinkable and the morally reprehensible have become commonplace in the fight to stay alive in this environment, where no one knows what new trauma 
tomorrow may bring. Why worry about a hypothetical sickness that could be caused by drinking unsafe water or eating spoiled food? Recourse to prostitution and therefore potential exposure to HIV/AIDS in order to buy food for dinner follows the same logic." While such phrasing might catch the reader's attention, it offers little insight into the complex choices people make. Moreover it makes it difficult for the reader to distinguish whether the authors are perpetuating the narrative tropes often used to characterize the Congo, or actively writing against it.

The more fundamental critique however pertains to the use of story-telling in this book. Centring people's experiences is necessary and important, and I wish it happened more often in the academic production on the eastern Congo. Yet, this book also shows the potential downsides of such an approach. The authors claim that the book is "the first urban sociology of this unsettling danger-fraught social crucible". While it certainly offers an interesting insight into the social texture of Goma, the claim that this is an urban sociology is open to question.

The authors chose to let the stories speak for themselves. Taking people's stories at face value is not without its perils. This is clear when it comes to the way the authors deal with ethnicity and identity. Several life histories make reference to ethnicity. In chapter 4 for example ('A stonecutter's paradise') Celestin and Mituga explain they are happy they overcame ethnic divisions "that complicate this city where tribalism reigns". The authors do not - here, and in other places in the book - contextualize or nuance such statements, reproducing images of Goma and the wider eastern DRC plagued by tribalism and ethnic antagonism.

Ethnicity plays a significant role in social interactions, and often plays an important role in conflicts, both in Goma and the wider eastern DRC. Yet, from a book claiming to be an urban sociology one expects that the role of identity in the urban context would be dealt with more carefully. Why not emphasize ethnicity has been mobilized politically by politicians during and even before the conflicts in the DRC, or elaborate more on the historical production of ethnic identities? The authors call Rwanda for example the "land of the brothers we don't like". Relationships between Rwanda and Congo have been, and still often are, fraught with tension. However, not explaining where this enmity comes from, depoliticizes relations between the two countries and ignores that this has not always been the case, but is the outcome of specific historical processes and years of conflict.

To give another illustration, explaining in the glossary that Banyamulenge is "a term used to identify ethnic Tutsis of questionable Congolese citizenship" [own emphasis] is equally problematic. Do the authors agree that Banyamulenge citizenship is questionable - a very political statement? While some have cast doubt on the citizenship of the Banyamulenge within specific historical and political contexts in which citizenship was (ab)used as a political tool, Banyamulenge citizenship is recognized by law. This book is praiseworthy because it puts the experiences of the inhabitants of Goma centre stage, and gives a rare insight into their lives. At the same time, allowing these life-histories to speak for themselves raises problems. They are not 
merely individual stories, but also the product of a social and political present. Not addressing the context in which they have been produced, and failing to make the link between perceptions and the impact they have on lived social realities risks reproducing politicized accounts of Goma's history. The interpretation of these live-stories should not be left entirely to $\mathrm{a}(\mathrm{n})$ (uninformed) reader.

Thus, Goma - Stories of strength and sorrow raises an important question. How are we to write (hi)stories that privilege people's lived experiences, contextualize them within the context that has produced them, without delegitimizing these experiences? How do social scientists give voice to these experiences, frame them, without overriding the voices they interpret, but also without reiterating damaging tropes and stereotypes? This book raises fundamental questions, but it does not go far enough to effectively address them.

\section{Gillian Mathys}

Department of History, Ghent University 